Revista Brasileira de Agricultura Irrigada v.4, n.2, p.78-81, 2010

ISSN 1982-7679 (On-line)

Fortaleza, CE, INOVAGRI - http://www.inovagri.org.br/rbai

Protocolo 410 - W - 05/04/2010 Aprovado em 10/06/2010

\title{
DESEMPENHO DE UM SISTEMA DE IRRIGAÇÃO AUTOMATIZADO ATRAVÉS DA TENSÃO DE ÁGUA NO SOLO
}

\author{
Antônia Bruna Mesquita Macedo ${ }^{1}$, Fábio Rodrigues de Miranda $^{2}$, Raimundo Rodrigues \\ Gomes Filho ${ }^{3}$, Adunias dos Santos Teixeira ${ }^{4}$, José Aglodoaldo H. Cavalcante Júnior ${ }^{5}$, \\ Haroldo Ferreira de Araújo ${ }^{6}$.
}

\footnotetext{
${ }^{1}$ Mestre em Irrigação e Drenagem, Departamento de Engenharia Agrícola, UFC, Caixa Postal 12168, CEP: 60 455-970, Fortaleza, CE, Fone: (85) 99229281, e-mail: brunammacedo@gmail.com

${ }^{2}$ Pesquisador, Embrapa Agroindústria Tropical, Fortaleza, CE, e-mail: fabio@cnpat.embrapa.br

${ }^{3}$ Professor Adjunto, Universidade Federal de Goiás, UFG, Jataí, GO, e-mail: rrgomesfilho@bol.com.br

${ }^{4}$ Professor, PhD., Departamento de Engenharia Agrícola, UFC, Fortaleza,CE, e-mail: adunias@ufc.br

${ }^{5}$ Doutorando em Engenharia Agrícola, Departamento de Engenharia Agrícola, UFC, Fortaleza, CE, e-mail: cavalcante_junior@hotmail.com

${ }^{6}$ Mestrando em Engenharia Agrícola, Departamento de Engenharia Agrícola, UFC, Fortaleza, CE, e-mail: haroldfa@gmail.com
}

\section{RESUMO}

$\mathrm{Na}$ irrigação de precisão, a conservação de energia e a economia de água podem ser alcançadas de forma eficiente através do aperfeiçoamento da estratégia de controle do sistema de irrigação. Diante disso, o trabalho teve como objetivo avaliar o desempenho de um sistema de irrigação automatizado através da tensão de água no solo. O experimento foi realizado em Limoeiro do Norte, Ceará, utilizando a cultivar Pacovan Ken, irrigada por microaspersão. Um sistema automático de controle em malha fechada, composto por sensores, multiplexadores, um datalogger e um controlador de carga, foi utilizado para monitorar as tensões da água no solo e controlar as irrigações, acionando uma motobomba sempre que as tensões atingissem os níveis pré-estabelecidos para cada tratamento. Os tratamentos consistiram em iniciar as irrigações quando a tensão da água na zona radicular da cultura (0-0,4 m) atingisse 15, 30, 45 e $60 \mathrm{kPa}$. O sistema automatizado apresentou deficiência em alguns aspectos, provocando a aplicação de água em déficit e em excesso, o que prejudicou o rendimento da cultura. No entanto, quando os sensores funcionaram perfeitamente se mostrou um sistema bastante prático.

Palavras-Chave: automação, sensores de umidade, potencial matricial.

\section{ABSTRACT}

PERFORMANCE OF AN AUTOMATIC IRRIGATION SYSTEM THROUGH THE SOILWATER TENSION 


\section{DESEMPENHO DE UM SISTEMA DE IRRIGAÇÃO AUTOMATIZADO ATRAVÉS DA TENSÃO DE ÁGUA NO SOLO}

In precision irrigation, conservation of energy and water savings can be achieved efficiently by improving the control strategy of the irrigation system. The study aimed to evaluate the performance of an automated irrigation system through the soil water tension. The experiment was conducted in Limoeiro, Ceará, using Pacovan Ken, irrigated by micro sprinklers. An automatic closed-loop control, consisting of sensors, multiplexer, a data logger and a charge controller was used to monitor the stresses of soil water and irrigation control, activating a pump when the tension reached the pre - established for each treatment. The treatments consisted of irrigation start when the tension of the water in the root zone of the culture $(0-0,4$ $\mathrm{m})$ reached 15, 30, 45 and $60 \mathrm{kPa}$. The automated system showed deficiency in some aspects, causing the application of water deficit and excess, which adversely affected crop yield. However, when the sensors worked perfectly proved a very practical system.

Keywords: automation, moisture sensors, matric potential.

\section{INTRODUÇÃO}

Para sistemas de irrigação capazes de aplicar água com alta freqüência, como os sistemas de microirrigação utilizados na cultura da bananeira, o monitoramento da tensão de água no solo é uma das formas mais adequadas de manejo (PHENE; HOWELL, 1984).

Entre os sensores mais utilizados no monitoramento da tensão da água no solo citam-se os tensiômetros e os sensores de matriz granular. Os tensiômetros apresentam limitações para o uso em sistemas automatizados de controle da irrigação em virtude da necessidade freqüente de manutenção. Os sensores do tipo matriz granular são relativamente baratos, não requerem manutenção e podem ser facilmente conectados a sistemas eletrônicos de aquisição de dados e de controle.

Quando a automação de um sistema de irrigação é bem programada, apresenta algumas vantagens em relação aos sistemas tradicionais que demandam mão-de-obra para serem acionados, pois além do custo de se dispor de operadores para essa função, o acionamento manual se torna irregular, permitindo que se esgote grande parcela da água disponível armazenada entre uma irrigação e outra (MEDICE, 1997). Desse modo, o objetivo do presente estudo foi avaliar o desempenho de um sistema de irrigação automatizado através da tensão de água no solo durante dois ciclos de produção da bananeira.

\section{MATERIAIS E MÉTODOS}

O experimento foi realizado em um lote de produtor, no Distrito de Irrigação Jaguaribe-Apodi, no município de Limoeiro do Norte, Estado do Ceará, Brasil; (latitude $05^{\circ} 08^{\prime} \mathrm{S}$, longitude $37^{\circ} 59^{\prime}$ $\mathrm{W}$, altitude $160 \mathrm{~m}$ ). A região apresenta clima quente e semi-árido, sendo classificado, segundo Köppen, como BSw'h'. O solo foi classificado como Cambissolo, textura franco argilosa.

Utilizou-se a cultivar de bananeira Pacovan Ken, plantada em novembro de 2005, em espaçamento de fileiras duplas $(4,0 \times 2,5 \times$ $2,0 \mathrm{~m})$, irrigada por microaspersão. Um sistema automático em malha fechada foi utilizado para controle das irrigações, sendo constituído por: 48 sensores de tensão da água no solo tipo matriz granular (modelo Watermark $^{\circledR}$ 200SS, Irronmeter), três sensores de temperatura do solo (Termistor C100F103G, Thermometrics), conectados a um datalogger (CR10X, Campbell Scientific), através de dois multiplexadores (AM 16/32, Campbell Scientific), possuindo ainda um controlador de carga (SDM-CD16AC, Campbell Scientific), chaves de partida e bombas centrífugas, conforme descrito por Canafístula et al. (2005). Os tratamentos (T1, T2, T3 e T4) consistiram em iniciar as 


\section{DESEMPENHO DE UM SISTEMA DE IRRIGAÇÃO AUTOMATIZADO ATRAVÉS DA TENSÃO DE ÁGUA NO SOLO}

irrigações quando a tensão da água na zona radicular da cultura $(0-0,4 \mathrm{~m})$ atingissem $15,30,45$ e $60 \mathrm{kPa}$. Foram instalados três sensores de tensão do solo na fileira dupla central de cada parcela experimental, a uma distância de $0,50 \mathrm{~m}$ do pseudocaule da planta, nas profundidades de 0,$10 ; 0,30 \mathrm{e}$ $0,50 \mathrm{~m}$, mesmas profundidades utilizadas para instalação dos sensores de temperatura.

O processo de controle das irrigações tinha início com a aquisição dos valores de temperatura e de resistência elétrica dos sensores Watermark através do datalogger para cálculo da tensão de água no solo. $\mathrm{O}$ datalogger foi programado para efetuar as leituras dos sensores a cada $60 \mathrm{~s}$ e sempre que a tensão de três dos quatros sensores do mesmo tratamento, instalados na profundidade de $0,10 \mathrm{~m}$ atingisse o limite pré-estabelecido, o sistema de irrigação do tratamento era acionado. O término da irrigação ocorria quando decorrido o tempo necessário para aplicar a lâmina de água requerida para elevar a umidade do solo à capacidade de campo (10 kPa) na zona radicular efetiva da cultura. Para $\mathrm{o}$ monitoramento dos volumes de água aplicados em cada tratamento utilizou-se hidrômetros.

\section{RESULTADOS E DISCUSSÃO}

Os valores de tensão de água no solo foram monitorados durante 510 dias, para os quatro tratamentos. As figuras mostram a variação de tensão dos sensores de umidade do solo instalados a 0,10;0,30 e $0,50 \mathrm{~m}$, no entanto a irrigação era baseada principalmente nos sensores que se encontravam na camada de solo ( 0 a 0,40 $\mathrm{m})$. Para o tratamento que iniciava as irrigações quando a tensão de água no solo chegava a $15 \mathrm{kPa}$, pode-se observar (Figura 1) que os sensores apresentaram falhas de leitura, proporcionando tanto irrigações com déficit e com excesso na aplicação de água, obtendo uma lâmina total de irrigação de $2284,36 \mathrm{~mm}$.

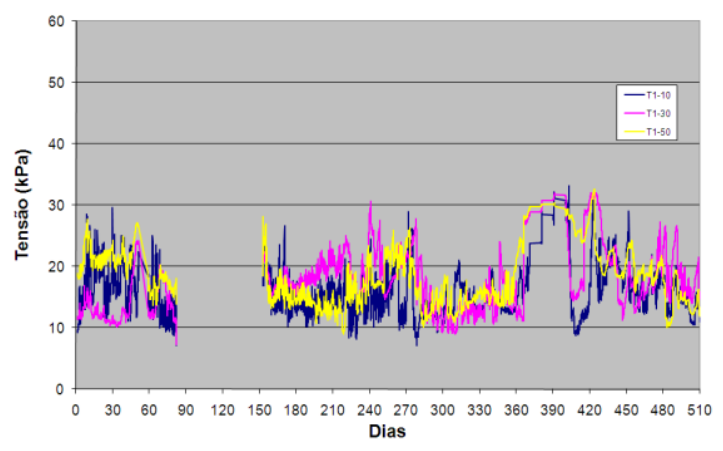

Figura 1. Variação da tensão de água no solo para o tratamento que iniciava a irrigação em $15 \mathrm{kPa}$ (T1), durante dois ciclos de produção da bananeira.

Os tratamentos T2 (Figura 2) e T4 (Figura 4) apresentaram uma variação esperada de acordo com a tensão estabelecida para início das irrigações, sendo aplicada uma lâmina total de irrigação de 2000,27 e 1296,09 mm, respectivamente. Já o tratamento T3 (Figura 3) que iniciava as irrigações quando a tensão de água no solo chegava a $45 \mathrm{kPa}$, apresentou bastante oscilação dos valores de tensão principalmente nos sensores instalados a $0,10 \mathrm{~m}$ de profundidade, os responsáveis pelo controle das irrigações. Esse fato proporcionou um excesso de irrigação para esse tratamento, com lâmina total de 2649,07 mm para os dois ciclos da cultura, prejudicando sua produção.

A variação de comportamento dos sensores pode ser atribuída a vários fatores, dentre eles podemos destacar alguns: instalação inadequada, variação da uniformidade do solo, e interação com meio ambiente. Dessa forma, a escolha de dados através da analise do comportamento do sensor é relevante para o desempenho correto do sistema de irrigação automatizado (CANAFÍSTULA et al., 2005). 


\section{DESEMPENHO DE UM SISTEMA DE IRRIGAÇÃO AUTOMATIZADO ATRAVÉS DA TENSÃO DE ÁGUA NO SOLO}

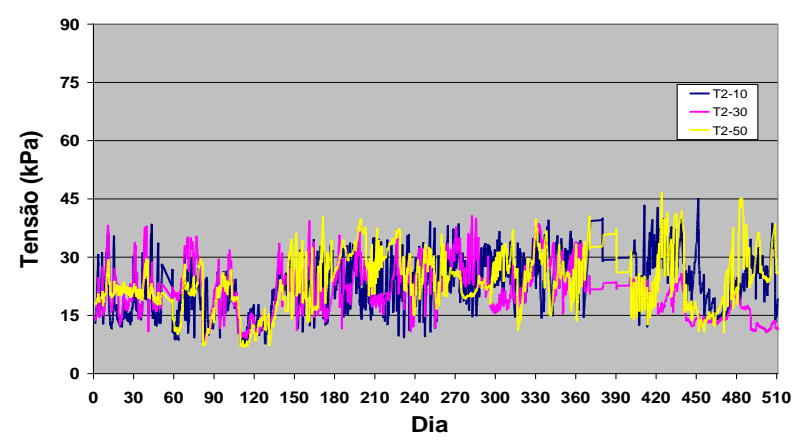

Figura 2. Variação da tensão de água no solo para o tratamento que iniciava a irrigação em $30 \mathrm{kPa}$ (T2), durante dois ciclos de produção da bananeira.

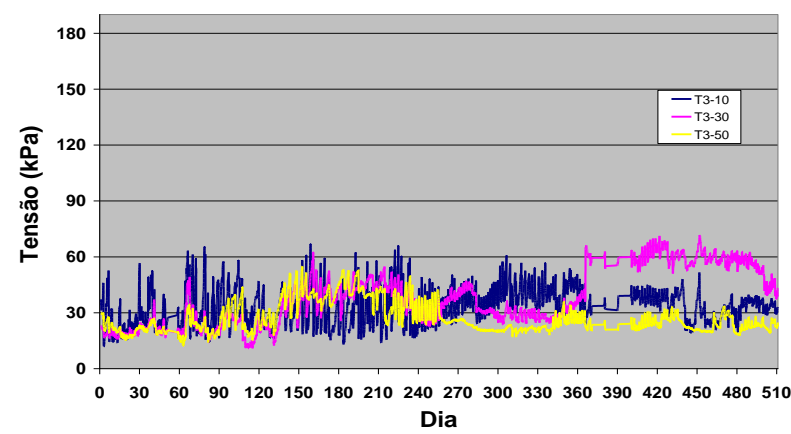

\section{CONCLUSSÕES}

O sistema automatizado de controle da irrigação através da tensão de água no solo apresentou deficiência em alguns aspectos, provocando a aplicação de água em déficit e em excesso, o que prejudicou o rendimento da cultura. No entanto, quando os sensores funcionaram perfeitamente se mostrou um sistema bastante prático.

\section{REFERÊNCIAS BIBLIOGRÁFICAS}

CANAFÍSTULA, F.J.F.; TEIXEIRA, A.S.; RIBEIRO, R.S.F; GONDIM, R.S.;
Figura 3. Variação da tensão de água no solo para o tratamento que iniciava a irrigação em $45 \mathrm{kPa}$ (T3), durante dois ciclos de produção da bananeira.

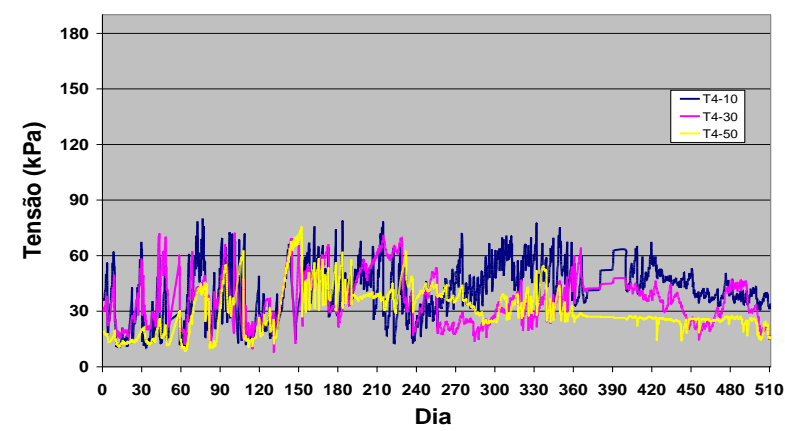

Figura 4. Variação da tensão de água no solo para o tratamento que iniciava a irrigação em $60 \mathrm{kPa}$ (T4), durante dois ciclos de produção da bananeira.

MIRANDA, F.R. Controle de malha fechada para irrigação de precisão. Item: Irrigação e Tecnologia Moderna, v. 67, p. 82-85, 2005.

MEDICE, L.O. Acionador automático de sistemas de irrigação. Revista da Propriedade Industrial, Rio de Janeiro, n.1399, s.p., 1997.

PHENE, C.J.; HOWELL, T.A. Soil sensor control of high-frequency irrigation systems. Transactions of the ASAE, v. 27, n. 2, p. 392-396, 1984. 